\title{
Histomorphological patterns of endometrium in abnormal uterine bleeding
}

\author{
Roopmala M. ${ }^{1}$, Thamilselvi R. ${ }^{2}$, Poovizhi I. ${ }^{3}$
}

${ }^{1}$ Dr. Roopmala Murugan, Assistant Professor, ${ }^{2}$ Dr. Thamilselvi Ramachandran, Professor and Head, ${ }^{3}$ Dr. Poovizhi Inbasekaran, Assistant Professor, all authors are affiliated with Department of Pathology, Vinayaka Mission's Kirupananda Variyar Medical College and Hospital, Salem, Tamil Nadu, India.

Corresponding Author: Dr. Roopmala Murugan, Assistant Professor, Department of Pathology, Vinayaka Mission's Kirupananda Variyar Medical College and Hospital, Salem, Tamil Nadu, India. E-mail: rubynandaarya@gmail.com

\begin{abstract}
Background: Abnormal uterine bleeding (AUB) is a common gynecological complaint, for which histopathological examination of endometrium is the gold standard tool in diagnostics. Aim of this study is to analyze various histomorphological patterns of endometrium in patients belonging to various age groups with abnormal uterine bleeding. Materials and Methods: A retrospective study of 174 patients presenting with abnormal uterine bleeding underwent endometrial sampling during a period of 2 years from September 2017 to August 2019 at VMKVMCH, Department of Pathology, were analyzed. Endometrial tissue received by sampling procedures such as dilatation and curettage (D \& C), endometrial biopsy and fractional curettage were all submitted entirely for processing in the Department of Pathology. Patient data were collected, and slides were reviewed. Result: A total of 174 cases were analyzed. Patients' age ranged from 15 to 65 years. The predominant endometrial finding was proliferative endometrium 54 cases (31\%) followed by secretory endometrium 50 cases (28.7\%). Malignant lesions were seen in 5 cases $(2.87 \%)$ in patients more than 49 years of age. Among the organic causes, polyps were the commonest 8 cases $(4.59 \%)$. Adequate samples were obtained from $91 \%$ of cases while $9 \%$ of cases' samples were inadequate for opinion. Conclusion: Histopathological examination of endometrial samples should be done in patients with abnormal uterine bleeding, especially in women over 35 years of age to rule out malignancy and preneoplasia. Patients with no organic pathology had normal physiological patterns like proliferative endometrium, secretory endometrium and menstrual changes. Most common endometrial pathology in this series was endometrial polyp 8 cases $(4.59 \%)$.
\end{abstract}

Keywords: Abnormal uterine bleeding, Endometrial polyp, Endometrial adenocarcinoma.

\section{Introduction}

Abnormal Uterine Bleeding (AUB) is defined as any uterine bleeding that is more than the normal volume, of longer duration and varying in regularity or frequency [1]. AUB is a collective terminology that includes both organic and non-organic causes. The indications of endometrial biopsy or curettage are:

1. Determination of the causes of AUB.

2. Evaluation of endometrial status and histological dating in infertile women.

3. Evaluation of products of conception.

4. Assessment of response to hormonal therapy, as in case of estrogen replacement in perimenopausal and postmenopausal women and Tamoxifen therapy in breast cancer patients.

Manuscript received: $4^{\text {th }}$ September 2019

Reviewed: $14^{\text {th }}$ September 2019

Author Corrected: $20^{\text {th }}$ September 2019

Accepted for Publication: $24^{\text {th }}$ September 2019
5. To rule out hyperplasia or malignancy in patients with atypical glandular cells of undetermined significance (AGUS) on cervico-vaginal cytology.

6. Abnormal ultrasound findings like thickened endometrium in postmenopausal women [2]

It includes both Dysfunctional Uterine Bleeding (DUB) and bleeding from structural causes like fibroids, polyps, endometrial carcinoma and pregnancy complications [3]. Several terms are used to describe patterns of AUB. Menorrhagia refers to bleeding occurring at normal interval (21 to 35 days) but with heavy flow $(>80 \mathrm{ml})$ or duration $>7$ days.

Metrorrhagia is bleeding of any amount which is acyclic, and which occurs irregularly or continuously in between normal cycles. Bleeding occurring at irregular, noncyclical intervals and with heavy flow $(>80 \mathrm{ml})$ or

Pathology Update: Tropical Journal of Pathology \& Microbiology Available online at: www.medresearch.in 708 | P a g e 
duration $>7$ days is called menometrorrhagia. Polymenorrhea is cyclic bleeding which is normal in amount but occurs at too frequent intervals of less than 21 days. Oligomenorrhea describes bleeding occurring at intervals greater than 35 days. Post-menopausal bleeding (PMB) is bleeding occurring in a menopausal woman at least one year after the cessation of cycles. DUB is a diagnosis of exclusion [4]. The underlying disease can be detected by histological variations of endometrium taking into account the age of the woman, the phase of her menstrual cycle, and use of any exogenous hormones. Early evaluation in the perimeno-pausal and postmenopausal women is essential to confirm the exact nature of the lesion and to rule out malignancy [5].

\section{Materials and Methods}

Type of Study: A retrospective study was carried out.

Setting: At the Department of Pathology in Vinayaka Mission's Kirupananda Variyar Medical College and Hospital.

Duration of study: 2 years study from 1st September 2017 to 31 st August 2019.

Sample size: Total of 174 endometrial samples were collected from patients with AUB irrespective of age.

\section{Original Research Article}

Sampling Methods: Endometrial samples received at the department of Pathology were collected by Dilatation and curettage (D and C), endometrial biopsy and fractional curettage from women presenting with AUB

Inclusion Criteria: Patients with complaints of AUB.

\section{Exclusion criteria}

1. Patients with cervical and vaginal pathology.

2. Patients with systemic diseases like hemostatic disorders etc.

Data collection procedure: Data were collected in pathology laboratory for evaluation over a period of 2 years.

Patients' additional details were collected from the department of Medical records and the histo-pathological reports made on all these cases were collected from the Department of Pathology.

Data analysis procedure: The collected data were categorized on the basis of varying endometrial morphologies and the age pattern was analyzed in each category.

Ethical Consideration: Submitted.

\section{Results}

Total of 174 cases were analyzed, out of which 16 cases (9\%) had inadequate samples and 158 cases were adequate (91\%) and reported samples. Patients' age ranged from 15-65 years, most of the patients were in the 41-50 years (49.36\%) age group, followed by $31-40$ years $(30.37 \%)$

Out of the 158 cases reported, histopathological examination showed various patterns in AUB consisting of normal cyclic pattern showing proliferative, secretory, disordered proliferative, and lytic endometrial patterns in 108 cases. Complication of pregnancy evidenced by the presence of Products of Conception (POC) was seen in 1 case. Rest of the 49 cases showed disordered proliferative, pill induced, anovulatory or atrophic endometrium and organic causes like polyp, hyperplasia and adenocarcinoma (Table-1).

Table-1: Distribution of endometrial patterns in abnormal uterine bleeding $(n=158)$.

\begin{tabular}{|c|c|c|}
\hline Endometrial patterns & Number of patients & Percentage (\%) \\
\hline Proliferative phase & 54 & 34.17 \\
\hline Secretory phase & 50 & 31.64 \\
\hline Disordered proliferative phase & 20 & 12.65 \\
\hline Polyp & 8 & 5.06 \\
\hline Hyperplasia & 6 & 3.79 \\
\hline Pill endometrium & 5 & 3.16 \\
\hline Adenocarcinoma & 5 & 3.16 \\
\hline Lytic endometrium & 4 & 2.53 \\
\hline Anovulatory endometrium & 4 & 2.53 \\
\hline Atrophic endometrium & 1 & 0.63 \\
\hline Products of Conception & 1 & 0.63 \\
\hline
\end{tabular}




\section{Original Research Article}

Commonest histomorphological pattern observed in this study was proliferative phase between the age group 23 - 55 years, followed by secretory phase between 15-55 years of age. Among the endometrial pathologies, polyp was seen in the age group between 30-57 years, hyperplasia in age group between 36-53 years and adenocarcinoma endometrium between 4957 years (Table-2).

Table-2: Comparison of endometrial pattern in various age groups $(n=158)$.

\begin{tabular}{|l|c|c|c|c|c|c|c|}
\hline \multirow{2}{*}{ Endometrial Patterns } & \multicolumn{9}{|c|}{ Age } \\
\cline { 2 - 9 } & $<\mathbf{2 0}$ & $\mathbf{2 1 - 3 0}$ & $\mathbf{3 1 - 4 0}$ & $\mathbf{4 1 - 5 0}$ & $\mathbf{5 1 - 6 0}$ & $\mathbf{6 1 - 7 0}$ & $\mathbf{7 1 - 8 0}$ \\
\hline Proliferative phase & Nil & 8 & 14 & 28 & 4 & Nil & Nil \\
\hline Secretory phase & 1 & 2 & 15 & 29 & 3 & Nil & Nil \\
\hline Disordered proliferative phase & Nil & 1 & 9 & 6 & 4 & Nil & Nil \\
\hline Polyp & Nil & 1 & 3 & 3 & 1 & Nil & Nil \\
\hline Hyperplasia & Nil & Nil & 2 & 3 & 1 & Nil & Nil \\
\hline Pill endometrium & Nil & Nil & 3 & 2 & Nil & Nil & Nil \\
\hline Adenocarcinoma & Nil & Nil & Nil & 1 & 4 & Nil & Nil \\
\hline Lytic endometrium & Nil & Nil & 1 & 3 & Nil & Nil & Nil \\
\hline Anovulatory endometrium & Nil & Nil & 1 & 3 & Nil & Nil & Nil \\
\hline Atrophic andometrium & Nil & Nil & Nil & Nil & Nil & Nil & 1 \\
\hline Products of Conception & Nil & 1 & Nil & Nil & Nil & Nil & Nil \\
\hline
\end{tabular}

\section{Discussion}

AUB accounts for almost $25 \%$ of gynecological operations and $20 \%$ of outpatient's visits [5]. Whenever an endometrial sample is taken for AUB, the gynecologist expects the following data:

To identify the presence of an organic lesion, such as pregnancy complications, inflammation or polyp.

1. Evidence or active or old glandular and stromal breakdown or bleeding

2. Evidence to suggest dysfunctional uterine bleeding.

3. Evidence to suggest hyperplasia or malignancy [2]

In this study, the histopathology of endometrium was studied to identify the cause and to observe the incidence of various endometrial patterns in different age groups.

In the present study, maximum number of AUB cases were in 41-50 years age group ( 85 cases-48.85\%), followed by 31 40 years age group (51 cases $-29.31 \%$ ). In the present study and most of the other such related studies have found a maximum incidence of AUB in the perimenopausal age group $[5,6,7,8]$. The reason behind it may be due to the fact that these patients are in their climacteric period, as women approach the menopause, cycles shorten and often become intermittently anovulatory due to a reduction in the number of graffian follicles and the estradiol level [9].

In the present study, out of 174 cases normal physiological changes like proliferative and secretory patterns were noted most commonly. Proliferative pattern was noted most commonly in 54 cases (31\%). Second most common feature was secretory phase endometrium in 50 cases $(28.73 \%)$. Similar incidence was noted in other studies $[4,10,11,12,13]$. Proliferative endometrium were with the features such as tubular to slightly tortuous glands lined by pseudostratified tall columnar cells. The stroma appeared mildly oedematous to compact. The gland and stromal mitotic figures were scant to numerous based on the endometrial dating. Secretory endometrium was characterized by the presence of tortuous endometrial glands lined by tall columnar epithelial cells with subnuclear or supranuclear vacuoles, as the dating increased luminal secretions were also noted. The stroma appeared predecidualised along with prominent spiral arterioles on later dates. Mitosis appeared numerous to absent as the endometrial dating progressed.

Most common hormonal imbalance pattern noted was disordered proliferative endometrium in 20 cases $(11.49 \%)$, third most common pattern of all. Similar incidence was seen in the study conducted by Pratibha Singh [10] were $15.6 \%$ of cases showed disordered proliferative endometrium occupying the third position overall. Disordered proliferative endometrium has features similar to proliferative endometrium with glands lined by cytologically bland, pseudostratified, mitotically active epithelium with a normal gland stromal ratio. It differs from proliferative pattern by the presence of dyssynchronized glandular development. Disordered proliferative pattern lies at one end of the spectrum of proliferative lesions of endometrium that includes carcinoma at the other end with intervening stages of hyperplasia [5]. 


\section{Original Research Article}

Most common organic pathology noted was benign endometrial polyp found in 8 cases (4.59\%), (Fig:1) whereas in studies conducted by Sujata Jetly [3] and K Sajitha [6], incidence of polyp was found to be $2.7 \%$ and $5.12 \%$ respectively. Endometrial polyps characterized by the presence of polypoid lesions with epithelium on three sides with fibrovascular stroma containing varying sized glands and thick-walled blood vessels [3].

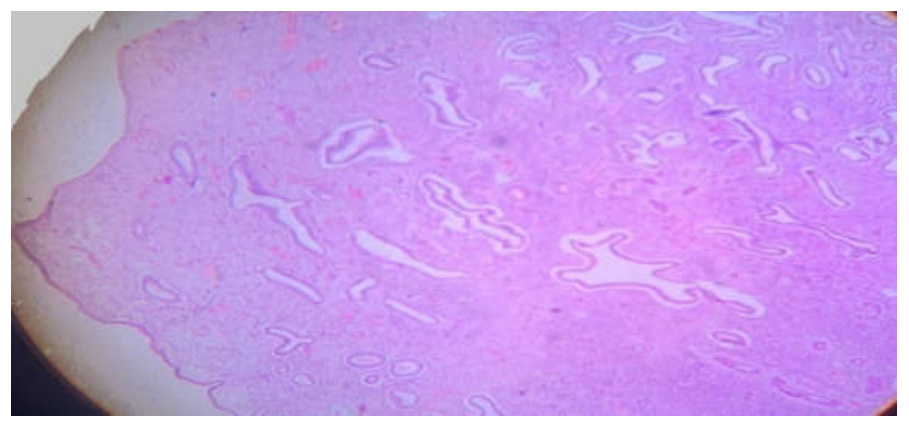

Fig-1: Endometrial Polyp with thick walled blood vessels and endometrial glands of varying sizes $(\mathrm{H} \& \mathrm{E}, 4 \mathrm{x})$

Endometrial hyperplasia (Fig: 2) was seen in 6 cases (3.44\%), out of which one case (16.66\%) was with atypia. Literature reports quite variable incidence of endometrial hyperplasia. Mariam Abid [13] and Swati Bapurao Mune [14] found it to be $5 \%$ and $22.2 \%$ respectively in their studies. Endometrial hyperplasia deserves special attention because of its relationship with endometrial carcinoma [14].

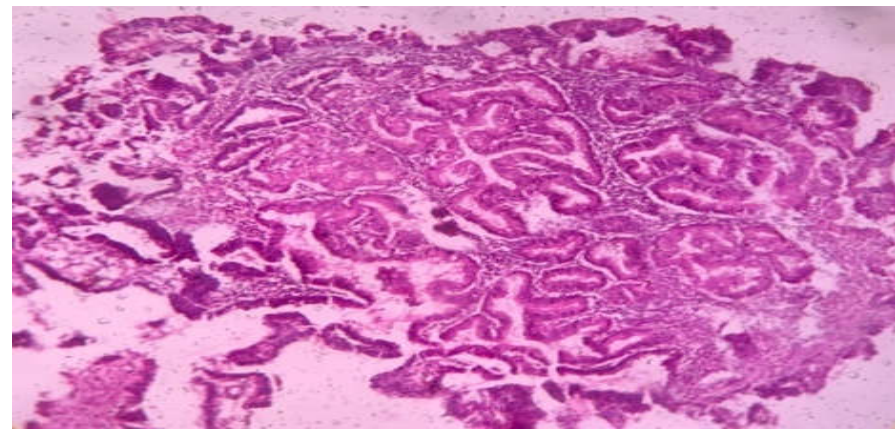

Fig-2: Complex hyperplasia without atypia - Back to back glands, complex branching, infoldings and minimal intervening stroma $(H \& E, 4 x)$

Endometrial malignancy was seen in 5 cases (2.87\%), out of which all were endometrial adenocarcinoma (Fig: 3 ), similarly Mariam Abid's study also had lower incidence of adenocarcinoma (2\%) in their study. The lower incidence of endometrial carcinoma could be justified by the fact that women are married in their early ages in our population, hence early childbearing and multiparity is common among them. Proliferative activity markedly declines during pregnancy and lactation explaining the lower incidence of hyperplastic and neoplastic lesions in our population [13].

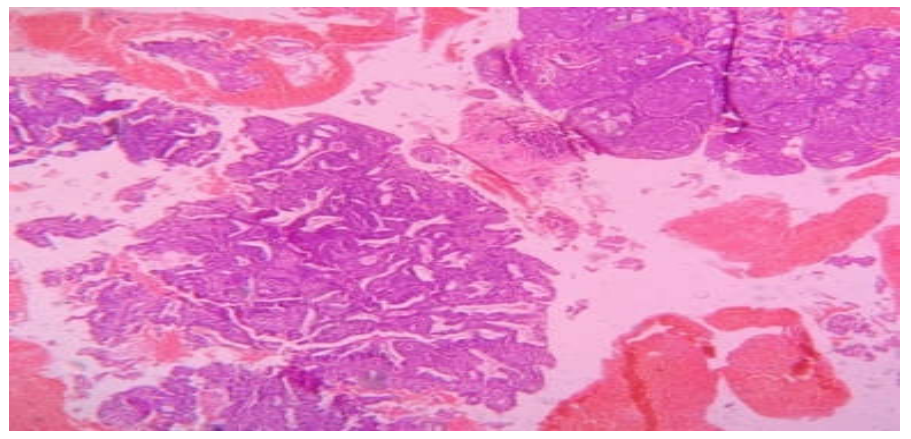

Fig 3: Adenocarcinoma with squamous metaplasia - back to back branching glands with no intervening stroma (H\&E, 4x) 


\section{Original Research Article}

The other causes of AUB included in the present study were pill endometrium in 5 cases $(2.87 \%)$, characterized by presence of inactive glands, some glands with abortive secretions, decidual reaction and thin walled blood vessels [5].

Lytic endometrium was seen in 4 cases $(2.29 \%)$, this endometrial pattern is one of the normal cyclic phases characterized by the presence of polymorphonuclear cells, lymphocytes invading into the stroma along with focal necrosis and haemorrhage [15].

Anovulatory endometrium in 4 cases $(2.29 \%)$, seen in perimenopausal women. In perimenopausal women anovulatory cycles are common and chronic anovulation is associated with irregular and unpredictable pattern of bleeding. In anovulatory cycles bleeding is due to the lack of progesterone caused by non-development of corpus luteum [9].

Atrophic endometrium in 1 case $(0.57 \%)$ was characterized by the presence of thin walled veins superficial to the cystically dilated endometrial glands that make them more vulnerable to injury.

POC in 1 case $(0.57 \%)$, this case presented with a history of AUB and did not have a history of pregnancy, histological examination revealed POC.

Among the 174 endometrial specimens received, 16 cases (9\%) had inadequate samples. This evidence supported the contention that any premalignant and malignant pathology could have been missed out. This should have been rectified by further endometrial sampling, outpatient hysteroscopy, transvaginal ultrasonography or a combination of these. Limitation of the present study was the technical failure in performing the endometrial biopsy in 16 cases (9\%) and further failure in obtaining the endometrial re-sampling.

\section{Conclusion}

Histopathological examination is mandatory in all patients with AUB. It is the major diagnostic tool in evaluation of AUB, as it shows a wide spectrum of patterns ranging from normal endometrium to malignancy. Hence it helps the physician to plan therapy for successful management of AUB and alleviates the need for unnecessary hysterectomy. In the present study, the most common organic cause for AUB was endometrial polyp (4.59\%), with a low incidence of malignancy in this population $(2.87 \%)$.

\section{What this study adds to the existing knowledge?}

- This study has shown that the commonest hormonal cause seen was Disordered proliferative endometrium, which lies on the one end of the spectrum progressing to hyperplasia and with malignancy on the other end of the spectrum

- The other histological patterns commonly seen among organic causes was polyps, which in post-menopausal females have chances to undergo malignant transformation

- Identification of the higher incidence of these entities in AUB emphasizes the importance of histopathological study of endometrial samples in AUB and also requires further research in view of environmental, dietary, therapeutic and sociopsychological factors.

\section{Author's contribution}

Dr. Roopmala Murugan: Contributed to conception, compilation, design of the study and manuscript preparation.

\section{Dr. Thamilselvi R, Dr. Roopmala M \& Dr. Poovizhi} I: Contributed in interpretation of the data.

Dr. Thamilselvi R: Final approval of the drafted article.

Findings: Nil; Conflict of Interest: None initiated Permission from IRB: Yes

\section{References}

1. Chitra T, Manjani S, Madhumittha R, Harke AB, Saravanan E, Karthik S. Histopathology of endometrial curettings in perimenopausal women with abnormal uterine bleeding. J. Evolution Med. Dent. Sci.2016;5 (24): 1285-1290. doi: 10.14260/jemds/2016/301

2. Mazur M, Kurman RJ. Diagnosis of endometrial biopsies and curettings: a practical approach. Springer Science \& Business Media; 2005.

3. Jetley S, Rana S, Jairajpuri ZS. Morphological spectrum of endometrial pathology in middle-aged women with atypical uterine bleeding: A study of 219 cases.J Midlife Health. 2013;4(4):216-220. doi: 10.4103 /0976-7800.122242 
4. Bhatta S, Sinha AK. Histopathological study of endometrium in abnormal uterine bleeding. J Pathol Nepal. 2012;2(4):297-300. doi: https://doi.org/ 10.3126 /jpn.v2i4.6882

5. Sajitha K, Padma SK, Shetty KJ, Prasad HLK, Permi HS, Hegde P. Study of histopathological patterns of endometrium in abnormal uterine bleeding. Chris Med J Health Res. 2014;1(2):76-81. doi: 10.4103/2348-3334. 134265.

6. Azim P, Mumtaz MK, Sharif N, Khattak E. Evaluation of abnormal uterine bleeding on endometrial biopsies. Isra Med J. 2011;3(3):84-87.

7. Khan S, Hameed S, Umber A. Histopathological pattern of endometrium on diagnostic $\mathrm{D} \& \mathrm{C}$ in patients with abnormal uterine bleeding. Ann King Edward Med Univers. 2011;17(2):166. doi: https://doi.org/10.21649/ akemu. v17i2.293

8. Bhosle A, Fonseca M. Evaluation and histopathological correlation of abnormal uterine bleeding in perimenopausal women. Bombay Hosp J. 2010;52 (1):69-72.

9. Puvitha RD, Elavarasan T, Shruthi MS, Shylaja S. Histopathological Study of Endometrium in Abnormal Uterine Bleeding. An Experience in a Tertiary Care Centre of Rural South India. Nat J Basic Med Sci. 2017;8:32-38.

\section{Original Research Article}

10. Singh P. Abnormal Uterine Bleeding-evaluation by Endometrial Aspiration. J Mid-life Health. 2018; 9(1): 32-35. doi: 10.4103/jmh.JMH_109_17

11. Doraiswami S, Johnson T, Rao S, Rajkumar A, Vijayaraghavan J, Panicker VK. Study of endometrial pathology in abnormal uterine bleeding. J Obstet Gynecol India. 2011; 61(4): 426-430. doi: 10.1007/ s13224-011-0047-2. Epub 2011 Sep 22.

12. Shajitha S., Sangeereni M, Mallika A. Study of endometrial pathology in abnormal uterine bleeding. Int J Curr Med Sci. 2017;7:324-326. doi: http://dx.doi.org/ 10.24327/ijcmes2017.07100025.

13. Abid M, Hashmi AA, Khan M. Clinical pattern and spectrum of endometrial pathologies in patients with abnormal uterine bleeding in Pakistan: need to adopt a more conservative approach to treatment. BMC Women's Health. 2014;14:132. doi: 10.1186/s12905014-0132-7

14. Mune SB, Karche AG. Histopathological patterns of endometrial lesions in patients with abnormal uterine Bleeding in rural area of Western Maharashtra. Indian J Pathol Oncol. 2016;3(4).665-672. doi: 10.5958/23946792. 2016.00124.1

15. Noyes RW, Hertig AT, Rock J. Dating the endometrial biopsy. Am J Obstet Gynecol. 1975;122 (2): 262-

263. doi: https://doi.org/10.1016/S0002-9378(16) $33500-1$

\section{How to cite this article?}

Roopmala M, Thamilselvi R, Poovizhi I. Histomorphological patterns of endometrium in abnormal uterine bleeding. Trop J Path Micro 2019;5(9):708-713.doi:10.17511/jopm.2019.i09.15. 